\title{
Putative consequences of exposure to Helicobacter pylori infection in patients with coronary heart disease in terms of humoral immune response and inflammation
}

\author{
Agnieszka Matusiak ${ }^{1}$, Maciej Chałubiński², Marlena Broncel², Tomasz Rechciński \\ Karolina Rudnicka ${ }^{1}$, Eliza Miszczyk ${ }^{1}$, Maria Walencka ${ }^{1}$, Dominik Strapagiel ${ }^{4}$, Adrian Gajewski ${ }^{1}$, \\ Magdalena Chmiela ${ }^{1}$
}

\begin{abstract}
${ }^{1}$ Laboratory of Gastroimmunology, Department of Immunology and Infectious Biology, Faculty of Biology and Environmental Protection, University of Lodz, Lodz, Poland 2Department of Internal Diseases and Clinical Pharmacology, Biegański Regional Specialty Hospital, Medical University of Lodz, Lodz, Poland

l Cardiology Clinic, Bieganski Regional Specialty Hospital, Medical University of Lodz, Lodz, Poland

${ }^{4}$ Biobank Lab, Department of Molecular Biophysics, Institute of Biophysics,

Faculty of Biology and Environmental Protection, University of Lodz, Lodz, Poland
\end{abstract}

Submitted: 27 February 2014

Accepted: 3 June 2014

Arch Med Sci 2016; 12, 1: 45-54

DOI: 10.5114 /aoms.2015.50772

Copyright (c) 2016 Termedia \& Banach

\section{Abstract}

Introduction: Pathogens, including Helicobacter pylori ( $\mathrm{Hp})$, have been suggested to contribute to the development of coronary heart disease (CHD), although the evidence still remains insufficient. The study was focused on the exposure of $\mathrm{CHD}$ patients to $\mathrm{Hp}$ and resulting anti-Hp heat shock protein $\mathrm{B}$ $\mathrm{HspB}$ antibody production in relation to the level of serum lipopolysaccharide binding protein (LBP) as a marker of inflammation.

Material and methods: One hundred seventy CHD patients and 58 non-CHD individuals participated in this study. Coronary angiography confirmed the atheromatic background of CHD. The panel of classical risk factors included: arterial hypertension, diabetes, total cholesterol, low-density lipoprotein $(\mathrm{LDL}) /$ high-density lipoprotein $(\mathrm{HDL})$ cholesterol, triglycerides, obesity and nicotinism. The Hp status was estimated by ${ }^{13} \mathrm{C}$ urea breath test and serology. Immunoblot and ELISA were used for screening the sera samples for anti-Hp HspB immunoglobulins (Igs) and LBP.

Results: Coronary heart disease patients were exposed to Hp more frequently than non-CHD individuals. This was associated with increased levels of specific anti-Hp IgG2 and IgA as well as total IgA. Hp infected CHD and nonCHD donors produced anti-Hp HspB IgG cross-reacting with human Hsp 60. In CHD patients the LBP level was significantly higher in comparison to non$\mathrm{CHD}$ donors. This was related to the severity of the disease. Type I Hp strains stimulated higher LBP levels than less pathogenic type II isolates.

Conclusions: Lipopolysaccharide binding protein secreted in excess together with anti-Hp HspB, cross-reacting with human Hsp60, may increase the risk of vascular pathologies in $\mathrm{Hp}$-exposed CHD patients.

Key words: atherosclerosis, Helicobacter pylori, autoantibodies, heat shock protein, lipopolysaccharide binding protein.

\author{
Corresponding author: \\ Karolina Rudnicka \\ Laboratory \\ of Gastroimmunology \\ Department of Immunology \\ and Infectious Biology \\ Faculty of Biology \\ and Environmental Protection \\ University of Lodz \\ 12/16 Banacha St \\ 90-237 Lodz, Poland \\ Phone: +48 426354525 \\ E-mail: \\ rudnicka@biol.uni.lodz.pl
}




\section{Introduction}

Gastric ulcer disease and coronary heart disease (CHD) are chronic disorders posing a serious health threat in humans. Their common feature is a local inflammatory response within the gastric epithelium [1] or in vascular endothelium, respectively [2-6]. Conventional risk factors account only for part of the CHD incidence. The prevalence of atherosclerosis in CHD patients seems to be increased by a number of infections to which an individual has been exposed [7]. Pathogens may directly affect the vessel wall by inducing the formation of macrophage-derived foam cells or indirectly by initiation of the inflammatory and autoimmune processes or due to the modification of classic CHD risk factors. The role of inflammation in the pathogenesis of CHD is supported by the finding that levels of proinflammatory cytokines, including tumor necrosis factor (TNF)- $\alpha$, interleukin (IL)- 6 and IL-1 $\beta$, increase during heart failure. Elevated levels of such cytokines have been considered as independent predictors of cardiovascular events [8].

The results of pioneer [9] and recent studies $[10,11]$ showed the elevation of anti-Helicobacter pylori (Hp) Igs from $40 \%$ to $90 \%$ in CHD patients. Especially type I Hp strains, producing cytotoxin associated gene $A$ antigen (CagA) and vacuolating cytotoxin (VacA), so-called $\mathrm{CagA}^{+} \mathrm{VacA}^{+} \mathrm{Hp}$ strains, are considered to be involved in CHD. The process underlying this association is probably the low-grade persistent inflammation stimulated by Hp strains with this phenotype [12]. This linkage was also supported by the identification of Hp genomic material within the coronary arteries [13], upregulation of biochemical inflammatory parameters and coronary lumen reduction [14]. A significant association of $\mathrm{Hp}$ infection with elevated levels of low-density lipoprotein (LDL), C-reactive protein (CRP), homocysteine, fibrinogen, plasminogen as well as inflammatory cytokines and a higher incidence of diabetes have been shown [15-18]. However, the evidence still remains unsatisfactory [19]. In several studies, no association between $\mathrm{Hp}$ seropositivity and CHD incidence was found. Thus there was no consensus on the role of $\mathrm{Hp}$ infections in either causation or progression of CHD [20-22]. The main controversy concerned the magnitude of study groups and various systems of data analysis. However, recently it was found that in Central Africans seropositive for $\mathrm{Hp}$, very high levels of anti-Hp IgG were significantly associated with CHD. After adjustment for classic risk factors of $\mathrm{CHD}, \mathrm{Hp}$ infection was found to be an independent predictor of carotid plaque and stroke prevalence [10]. Exposure to $\mathrm{Hp}$ has been found to be a risk factor of stroke in Mexican Americans, and given the increased exposure to $\mathrm{Hp}$ in this popu- lation, it may contribute to ethnic susceptibility to stroke [11]. In the light of recent findings it can be suggested that $\mathrm{Hp}$ seropositivity may be a predictor in patients with long-term but not early unstable angina [23]. However, the results of Schöttker et al. [24] do not support the hypothesis that $\mathrm{Hp}$ infection and exposure to CagA are risk factors for cardiovascular diseases or mortality and suggest an inverse relationship between infection with $\mathrm{Hp}$ $\mathrm{CagA}^{+}$and fatal cardiovascular events.

In this study we asked whether CHD patients chronically exposed to $\mathrm{Hp}$-respond with specific anti-Hp Igs production. Attention was focused on the production of antibodies to $\mathrm{Hp}$ heat shock protein $\mathrm{B}(\mathrm{Hp} \mathrm{HspB})$ and their ability to cross-react with human recombinant Hsp60 (hr Hsp60) and the reference Mycobacterium bovis Hsp65 (Mb Hsp65). The relation between exposure to $\mathrm{Hp}$ and levels of lipopolysaccharide binding protein (LBP) was considered as a marker of ongoing inflammation caused by tissue damage or bacterial infections. Recently it has been shown that the acute phase proteins can play a role of endogenous ligands for pattern recognition receptors (PRR) potentially involved in the pathogenesis of cardiovascular diseases [25]. We asked whether LBP levels might be influenced by type I Hp strains, which induce a stronger inflammatory response than CagA negative isolates.

\section{Material and methods}

\section{Subjects}

Subjects for the study were recruited from patients who were under the care of the $2^{\text {nd }}$ Cardiology Clinic of Bieganski Regional Specialty Hospital (Medical University of Lodz, Poland) and the Department of Internal Diseases and Clinical Pharmacology (Medical University in Lodz, Poland).

The CHD study group consisted of 170 patients (mean age: $59.7 \pm 7.4$, males comprised $65.3 \%$ ), 106 with unstable angina pectoris (UAP) and 64 after myocardial infarction (MI). The inclusion criteria for the CHD group constituted classic CHD risk factors and were as follows: arterial hypertension (intake of antihypertensive drugs prior to enrolment, systolic blood pressure > 140 or diastolic blood pressure >90 $\mathrm{mm} \mathrm{Hg}$ ), diabetes (glucose-reducing agents or insulin intake prior to enrolment), fasting glucose level (>126 mg/ dl $(7 \mathrm{mmol} / \mathrm{l})$ double checked), glycosylated hemoglobin $(\mathrm{Hb})$ level $(>7 \%$ or positive oral glucose tolerance test with 75 g glucose), dyslipidemia (hypolipidemic agents intake prior to enrolment), hyperlipidemia: total cholesterol level (>190 mg/ dl $(5.0 \mathrm{mmol} / \mathrm{l})$, LDL cholesterol level (>115 mg/dl (3.0 mmol/l)), high-density lipoprotein $(\mathrm{HDL})$ cholesterol $(<40 \mathrm{mg} / \mathrm{dl}(1.0 \mathrm{mmol} / \mathrm{dl}))$, or triglycerides 
(> $150 \mathrm{mg} / \mathrm{dl}(1.2 \mathrm{mmol} / \mathrm{l}))$, obesity measured by body mass index (BMI) (>32), nicotinism.

All CHD patients were examined by standardized coronary artery angiography. Angiographic results of $\mathrm{CHD}$ cases were further analyzed to calculate the Gensini score [26], and the reports were routinely used in both clinics. Multiple scoring systems are available for various angiographic coronary artery abnormalities. Neeland et al. compared several coronary angiographic scoring systems and concluded that although all of these scores correlated with each other, the Gensini was one of the most accurate [27]. The Gensini score provides valuable prognostic information on cardiovascular risk factors. This most widely used system takes into account: geometrically increasing severity of lesions: 25\%, 50\%, 75\%, 90\%, 99\% and $100 \%$ diameter reduction, cumulative effect of multiple lesions, location of lesions, influence of collaterals, and vessel graftability [27]. The index was calculated as a sum of multipliers dependent on the degree of lumen narrowing and localization of atherosclerotic plaque.

The control, non-CHD group consisted of 66 healthy individuals (mean age $56.5 \pm 5.2$, males comprised $63.6 \%$ ), with a negative history of cardiovascular diseases. The control group was selected on the basis of the exclusion of classic CHD risk factors: arterial hypertension, hyperlipidemia, diabetes, smoking or obesity. Eight individuals were excluded from the control group and further study, due to positive criteria for CHD.

All participants involved in the study were adults of European origin. All patients signed an informed consent form, and the study was approved by the Local Ethics Committee.

The blood samples were collected from the patients (CHD) and the controls (non-CHD) in a fasting state, on admission, before the medical and pharmacological intervention. The routine laboratory tests listed in the inclusion criteria (total cholesterol, lipoprotein fractions (LDL, HDL), triglyceride as well as glucose and glycosylated $\mathrm{Hb}$ levels) were evaluated in fresh blood samples using an automatic analyzer (Cobas 6000, Roche Diagnostics, Germany) in the Diagnostic Laboratory of Bieganski Regional Specialty Hospital in Lodz. Serum from the same blood sample was obtained within $1 \mathrm{~h}$, by $30 \mathrm{~min}$ incubation at room temperature and subsequent 30 min incubation at $4^{\circ} \mathrm{C}$ followed by centrifugation $\left(2000 \times \mathrm{g}, 10 \mathrm{~min}, 4^{\circ} \mathrm{C}\right)$. The sera were aliquoted and stored at $-80^{\circ} \mathrm{C}$ for further analysis. Samples were thawed directly before research measurements.

The $\mathrm{Hp}$ status was estimated by the ${ }^{13} \mathrm{C}$ urea breath test $\left({ }^{13} \mathrm{C}\right.$ UBT), and by enzyme linked immunosorbent assay (ELISA) for anti- $\mathrm{Hp} \operatorname{lgG}_{2}$ and IgA as well as by immunoblot for anti-Hp IgG, as previously described $[28,29]$, with anti- $\mathrm{Hp}_{\mathrm{IgG}}$ as
IgA subclasses being indicators of chronic $\mathrm{Hp}$ infection. Coincidence between the results obtained from ELISA and ${ }^{13} \mathrm{C}$ UBT, as well as between ELISA and immunoblot, was $98 \%$ [30].

\section{Detection of anti-Hp $\operatorname{lgG}$ and $\lg \mathrm{G}_{2} / \lg A$ by ELISA}

The ELISA assay was performed using 170 serum samples of CHD patients and 58 non-CHD individuals with a glycine acid extract (GE) from the reference Hp strain CCUG 17874 (Culture Collection, University of Gothenburg, Sweden) and rabbit anti-human IgG and IgA antibodies, or mouse monoclonal antibodies to a human $\operatorname{lgG}_{2}$ subclass conjugated with horseradish peroxidase (HRP) (Dako, Glostrup, Denmark) [29]. The cut-off $\mathrm{OD}_{450}$ value for anti-Hp IgG and $\operatorname{lgG}_{2}$ was 0.30 and 0.2 , respectively, and 0.34 for anti-Hp IgA. These markers of nonspecific ELISA reactions were derived from medium $\mathrm{OD}_{450}$ values supplemented with double SD for the wells coated with the GE and incubated with the HRP conjugated antibody, and chromogen-substrate solution. An immunoturbidimetric assay with anti-lgG or anti-lgA antiserum was used for estimation of the total concentrations of IgG or IgA in the serum samples (Sentinel Diagnostic, Milan, Italy). The reference values were in the range of $700-1600 \mathrm{mg} / \mathrm{dl}$ and $70-400$ $\mathrm{mg} / \mathrm{dl}$ for IgG and IgA, respectively.

\section{Specificity of IgG response to $\mathrm{Hp}$ antigens including $\mathrm{HspB}$ visualized by Western blot}

IgG against the Hp antigens CagA (120 kDa), VacA (87 kDa), UreB (66 kDa), HspB (60 kDa), Fla $(54,57 \mathrm{kDa})$, Ure $A(29 \mathrm{kDa})$ and proteins of 20 , 26, $35 \mathrm{kDa}$ were detected by immunoblot using 170 serum samples of CHD patients and 58 nonCHD donors (Milenia ID Blot H. pylori IgG kit, DPC Biermann GmbH, Bad Nauheim, Germany or ViroBlot anti-H. pylori IgG, Viro-Immun Labor-Diagnostika GmbH, Oberursel, Germany). The Hp infection was evaluated on the basis of the reactivity of serum samples with selected antigens, as recommended by the manufacturer. The summarized Western blot data (Milenia ID Blot) of selected serum samples from $H$. pylori infected and uninfected donors are shown in Figure 1. Infection with the $\mathrm{CagA}^{+} \mathrm{VacA}^{+} \mathrm{Hp}$ strain was confirmed by the detection of anti-CagA and anti-VacA antibodies reacting in Western blot with the proteins of $120 \mathrm{kDa}$ and $87 \mathrm{kDa}$, respectively. The semiquantitative analysis of anti-Hp HspB antibodies reacting in Western blot with the protein of $60 \mathrm{kDa}$ was performed using image processing and analysis in Java software ImageJ (http://rsb.info.nih.gov, National Institute of Health, Bethesda, Maryland, USA) with color intensity units (CIU) for the analysis. 


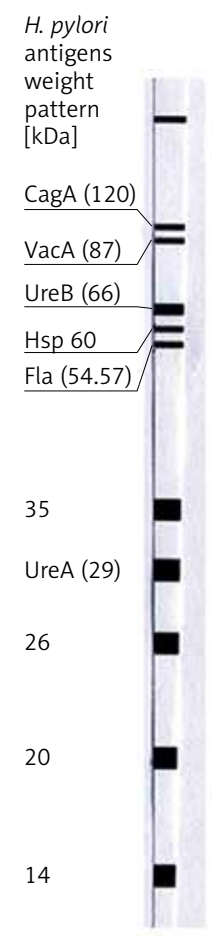

A

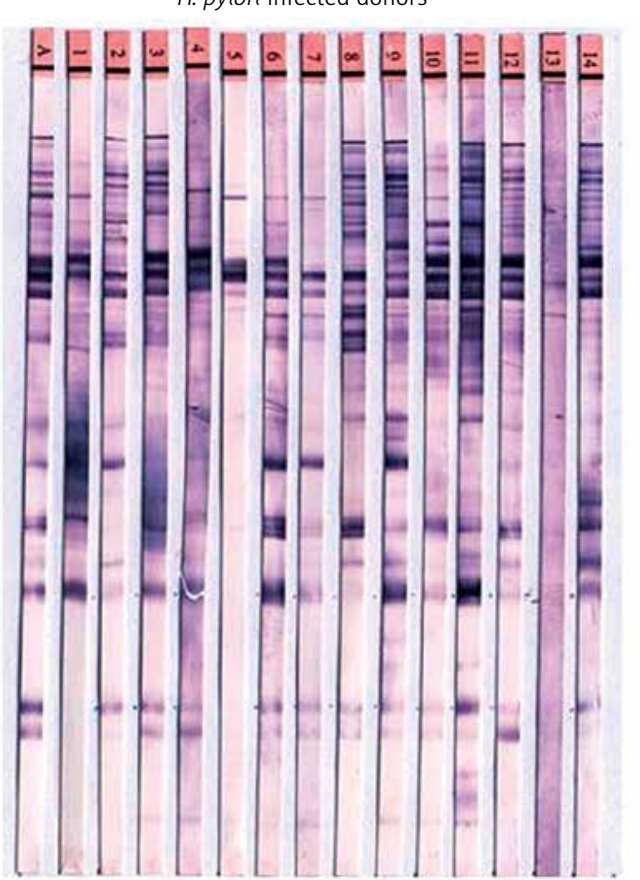

B

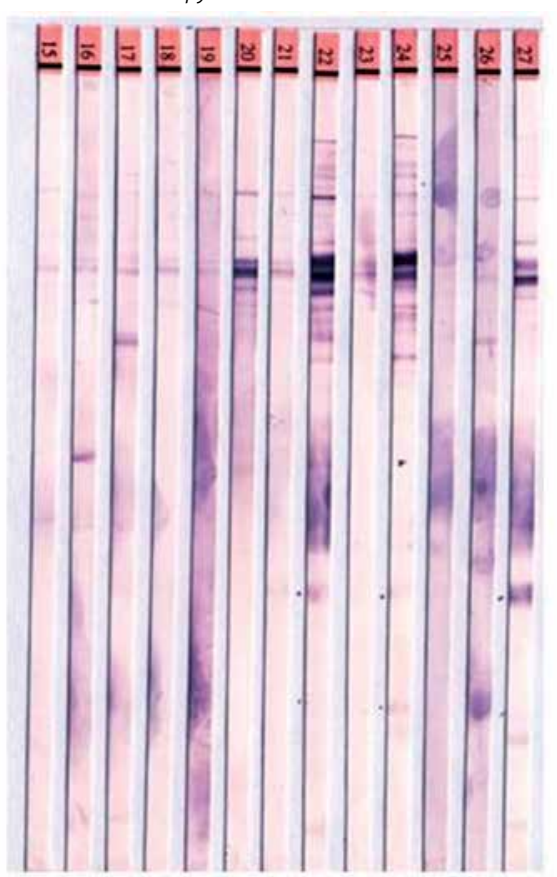

Figure 1. Summarized Western blot data of selected serum samples from H. pylori infected (A) and uninfected (B) individuals

Cytotoxin associated gene A antigen (CagA), vacuolating cytotoxin (VacA), urease (Ure), heat shock protein (Hsp), flagellin (Fla).

\section{Detection of anti-Mt Hsp65 IgG by ELISA}

The in-house ELISA assay was evaluated experimentally and performed using serum samples of 170 CHD and 58 non-CHD donors. Recombinant M. bovis BCG Hsp65 (StressMarq, Victoria, Cana$\mathrm{da}$ ), in a final concentration of $1 \mathrm{ng} / \mathrm{ml}$ (evaluated experimentally) in a $0.05 \mathrm{M}$ carbonate buffer, $\mathrm{pH}$ 9.6, was used for coating the wells $\left(18 \mathrm{~h}, 4^{\circ} \mathrm{C}\right)$. Phosphate buffered saline (PBS) with $1 \%$ bovine serum albumin (BSA) and 0.05\% Tween 80 (PBS/ $\mathrm{BSA} /$ Tween) was used for blocking, dilutions of serum samples (1:100) and HRP-conjugated rabbit antibodies to human IgG (Dako, Glostrup, Denmark) preparation. For the color reaction, chromogen $O$-phenylenediamine dihydrochloride (Sigma, St. Louis, MO, USA) was used in the $0.1 \mathrm{M}$ citric phosphate buffer, $\mathrm{pH} 5.0$ with $0.005 \mathrm{ml}$ of $30 \% \mathrm{H}_{2} \mathrm{O}_{2}$ per $\mathrm{ml}$. The cut-off $\mathrm{OD}_{450}$ value $(0.25)$ was the average absorbance supplemented with double SD for the wells coated with the antigen and containing HRP-conjugated secondary antibodies as well as chromogen-substrate solution. The results were evaluated quantitatively and expressed as $\mathrm{OD}_{450}$ absorbance readings above the cut-off value.

\section{Screening of serum samples for anti-rh Hsp60 IgG by ELISA}

The prevalence and concentrations of serum IgG specific for human Hsp60 were evaluated in 39 of CHD and 41 non-CHD sera samples by commercial ELISA assay as recommended by the manufacturer (Stressgen, Ann Arbor, USA). The detection limit of the assay was $2.88 \mathrm{ng} / \mathrm{ml}$.

\section{Cross-reactivity of anti-Hp HspB with human Hsp60 and M. bovis Hsp65}

To evaluate whether anti-Hp HspB IgG present in the serum samples from $\mathrm{Hp}$-exposed CHD patients (three serum samples) and non-CHD individuals (one serum sample) cross-reacted with human Hsp60 and with M. bovis Hsp65, all selected serum samples were absorbed: $1 \mathrm{~h}$ at $21^{\circ} \mathrm{C}$, $1 \mathrm{~h}$ at $37^{\circ} \mathrm{C}$ and $18 \mathrm{~h}$ at $4^{\circ} \mathrm{C}$ with a heat inactivated $\left(1 \mathrm{~h}, 80^{\circ} \mathrm{C}\right) \mathrm{Hp}$ reference strain, CCUG 17874. Non-absorbed and absorbed serum samples were used in the ELISA assays for the detection of IgG interacting with human $\mathrm{Hsp} 60$ and $M$. bovis Hsp65. The ELISA OD ${ }_{450}$ values for non-absorbed sera were considered as $100 \%$ reaction intensity in the assay, and were compared with the $\mathrm{OD}_{450}$ values obtained for the serum samples absorbed with $\mathrm{Hp}$. The final results were expressed as a percentage of ELISA assay inhibition.

\section{Quantitative determination of LBP}

The concentration of serum LBP was measured in all CHD, non-CHD samples and selected MI (34), UAP (93) samples by the ELISA (Human LBP ELISA Test Kit, HyCult Biotechnology, Uden, Netherlands) 
as recommended by the manufacturer. The sensitivity of the assay was $0.8 \mathrm{ng} / \mathrm{ml}$.

\section{Statistical analysis}

The Statistica 5.5 PL software (StatSoft, Poland) with non-parametric tests was used. To verify the potential differences between two statistically different populations, the Mann-Whitney $U$ test (for unpaired data) was used and frequency of analyzed parameters was analyzed by the chi-square $\left(\chi^{2}\right)$ test. Results were considered statistically significant when $p<0.05$.

\section{Results}

\section{Baseline characteristics of the study group}

Demographic data, prevalence of typical risk factors of atherosclerosis development, concomitant disorders and selected treatment of CHD patients are outlined in Table I.

\section{Anti-Hp $\operatorname{lgG}_{2}$ and IgA seroprevalence} as markers of long-term exposure to $\mathrm{Hp}$ in CHD and non-CHD subjects

The CHD patients were chronically exposed to $\mathrm{Hp}$ with higher frequency than non-CHD individ- uals, which was shown by independent detection of anti-Hp $\operatorname{lgG}_{2}$ (89\% vs. 69\%, $p=0.0004$ ) and anti-Hp IgA (65\% vs. $18 \%, p=0.0001)$ or simultaneous detection of anti-Hp $\operatorname{lgG}_{2}$ and $\mathrm{IgA}$ isotypes ( $55 \%$ vs. $27 \%, p=0.01)$. Higher frequency of $\mathrm{Hp}$ exposure in the CHD group was accompanied by significantly elevated anti-Hp $\operatorname{lgG}_{2}\left(\mathrm{OD}_{450} 0.586 \pm 0.461\right.$ vs. $0.367 \pm 0.346, p=$ $0.0006)$ and IgA $\left(\mathrm{OD}_{450} 0.820 \pm 0.532\right.$ vs. 0.529 $\pm 0.180, p=0.0220$ ). Moreover, in the CHD group an elevated level of total IgA was detected more frequently ( $26 \%$ vs. $6 \%, p=0.001)$ as compared to the non-CHD individuals. There was no difference between the CHD and non-CHD group in the total IgG levels.

\section{Levels of LBP in response to atherosclerosis} and $\mathrm{Hp}$ exposure

The LBP concentrations in the sera of CHD patients were significantly higher than in non-CHD individuals and were related to the severity of CHD disease: unstable angina pectoris and myocardial infarction (Figure $2 \mathrm{~A}$ ). In CHD patients the increased LBP production cannot be directly attributed to exposure to type I Hp strains (Figure $2 \mathrm{~B}$ ). However, such an effect was observed in non-CHD donors, where sera exposed to $\mathrm{CagA}^{+} \mathrm{VacA}^{+}$but not

Table I. Baseline demographics and clinical characteristics of patients with coronary heart disease (CHD) and nonCHD donors

\begin{tabular}{|c|c|c|c|}
\hline Characteristic & $\begin{array}{c}\text { CHD } \\
(n=170)\end{array}$ & $\begin{array}{l}\text { Non-CHD } \\
(n=58)\end{array}$ & $\begin{array}{c}\text { Statistical significance } \\
\text { ( } p \text {-value) }\end{array}$ \\
\hline \multicolumn{4}{|l|}{ Questionnaire: } \\
\hline Age [years] & $59.7 \pm 7.4$ & $56.5 \pm 5.2$ & Matched \\
\hline Females [\%] & $111(65.3 \%)$ & $42(63.6 \%)$ & Matched \\
\hline \multicolumn{4}{|l|}{ Coronary heart disease [\%]: } \\
\hline Myocardial infarction & 38.3 & 0 & \multirow{2}{*}{$<0.05$} \\
\hline Angina pectoris & 61.7 & 0 & \\
\hline \multicolumn{4}{|c|}{ Classic CHD risk factors/co-morbidities [\%]: } \\
\hline Arterial hypertension & 79.4 & 12.1 & \multirow{5}{*}{$<0.05$} \\
\hline Obesity (BMI > 32 kg/m²) & 10.0 & 3.0 & \\
\hline Smoking & 35.8 & 9.0 & \\
\hline Hyperlipidemia & 65.2 & 12.1 & \\
\hline Diabetes & 25.3 & 3.0 & \\
\hline \multicolumn{4}{|l|}{ Inflammatory markers [\%]: } \\
\hline $\operatorname{CRP}(>6 \mathrm{mg} / \mathrm{ml})$ & 34.1 & 0 & $<0.05$ \\
\hline \multicolumn{4}{|l|}{ Medication/surgery intervention [\%]: } \\
\hline Bypass grafting & 29.4 & 0 & \multirow{5}{*}{$<0.05$} \\
\hline High blood pressure medicines & 79.4 & 12.1 & \\
\hline Other specific medicines & 100.0 & 0 & \\
\hline Antidiabetics & 25.3 & 3.0 & \\
\hline Aspirin & 100.0 & 10.0 & \\
\hline
\end{tabular}


A

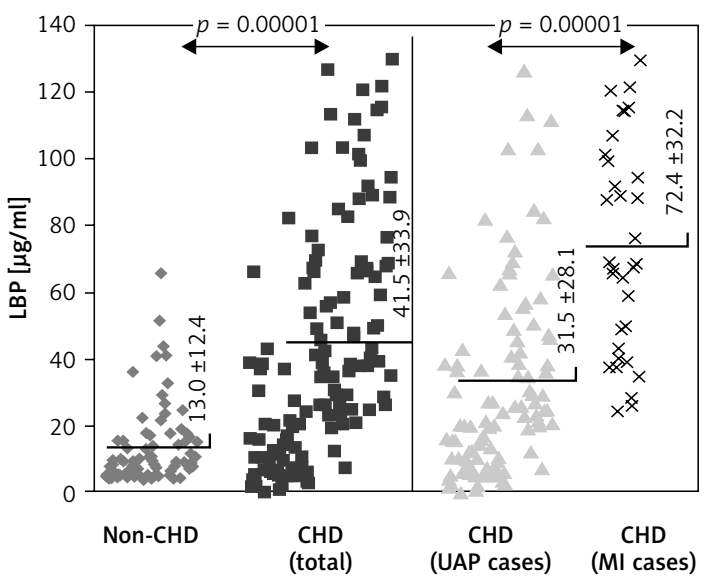

B

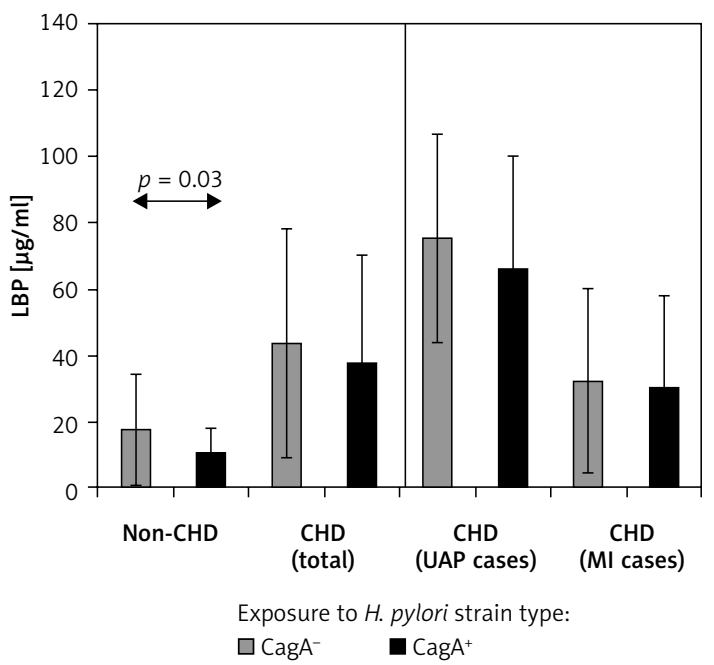

Figure 2. Concentrations of lipopolysaccharide binding protein (LBP) in the sera samples of the coronary heart disease (CHD) group in total, in CHD patients with unstable angina pectoris (UAP) and myocardial infarction (MI), as well as healthy non-CHD donors (A), infected with $\mathrm{CagA}^{+} \mathrm{VacA}^{+}$or $\mathrm{CagA}^{-} \mathrm{VacA}^{-}$H. pylori strains (B)

CagA- VacA- Hp strains contained higher concentrations of $\operatorname{LBP}(p=0.03)$ (Figure $2 \mathrm{~B})$.

\section{Distribution of IgG directed to human (rh Hsp60) and bacterial (Hp HspB, Mb Hsp65) Hsp proteins in CHD and non-CHD individuals}

All sera samples from cases (CHD) and controls (non-CHD) contained detectable levels of anti-hr Hsp60 lgG. However, the concentration of these antibodies in the CHD group was significantly higher as compared to healthy donors ( $p=0.0006)$ (Figure $3 \mathrm{~A}$ ). The anti-Mb Hsp65 IgG was detected in the majority of CHD sera (89\%), whereas only $65 \%$ of individuals of the non-CHD group produced IgG with such specificity $(p=0.0001)$. Also, the levels of anti-Mb Hsp65 IgG were significantly higher in CHD than non-CHD donors
( $p=0.00002$ ) (Figure 3 B). IgG anti-Hp HspB was detected by Western blot more frequently in the CHD cases (86\%) than in healthy controls (68\%) $(p=0.003)$. However, semiquantitative evaluation of the antibody production on the basis of color intensity units failed to show differences between the two studied groups. In order to evaluate whether anti-Hp HspB antibodies present in the sera of Hp-positive CHD and non-CHD individuals cross-react with hr Hsp60 and with Mb Hsp65, four serum samples positive for anti-Hp HspB in Western blot (one from a Hp-positive non-CHD donor and three from Hp-positive CHD patients) were absorbed with heat-inactivated $\mathrm{Hp}$ bacteria as described in the Material and Methods section. As shown in Figure 4, the absorption of sera with $\mathrm{Hp}$ bacteria diminished the intensity of IgG reactivity with Mb Hsp65 and with hr Hsp60 to approximately $43 \%$ and $31 \%$, respectively.
A

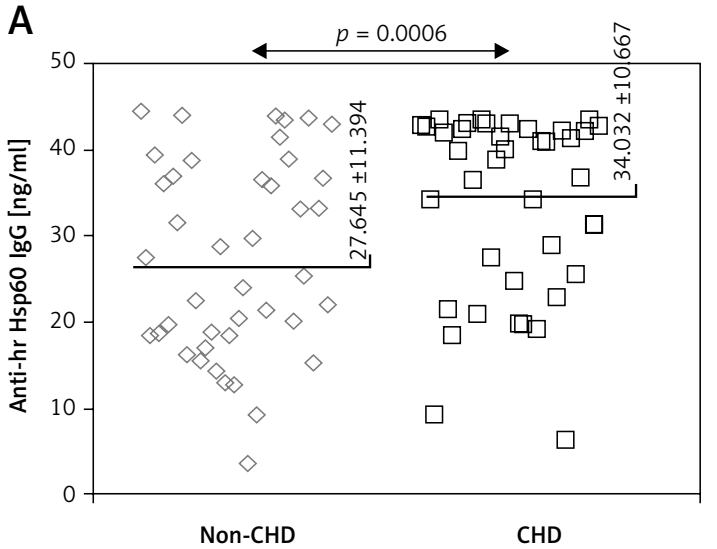

B

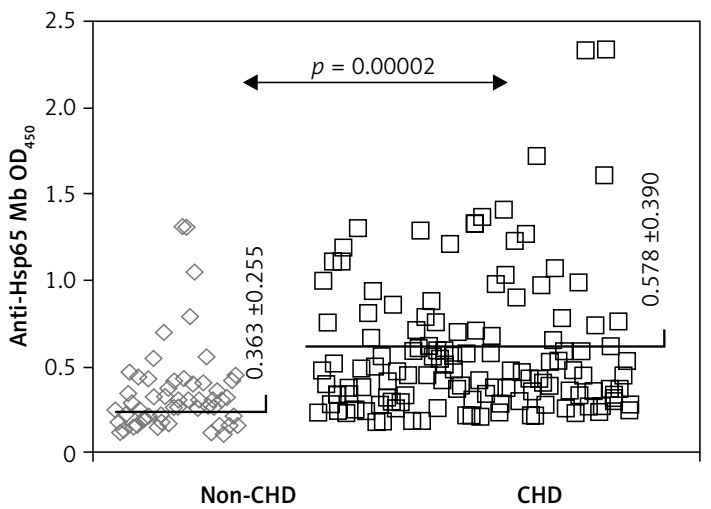

Figure 3. Distribution of IgG against human recombinant heat shock protein of $60 \mathrm{kDa}$ (hr Hsp60 - A) and M. bovis Hsp65 (Mb Hsp65 - B) in patients with coronary heart disease (CHD) and healthy non-CHD individuals, expressed as $\mathrm{ng} / \mathrm{ml}$ or optical density (OD) units, respectively 
A

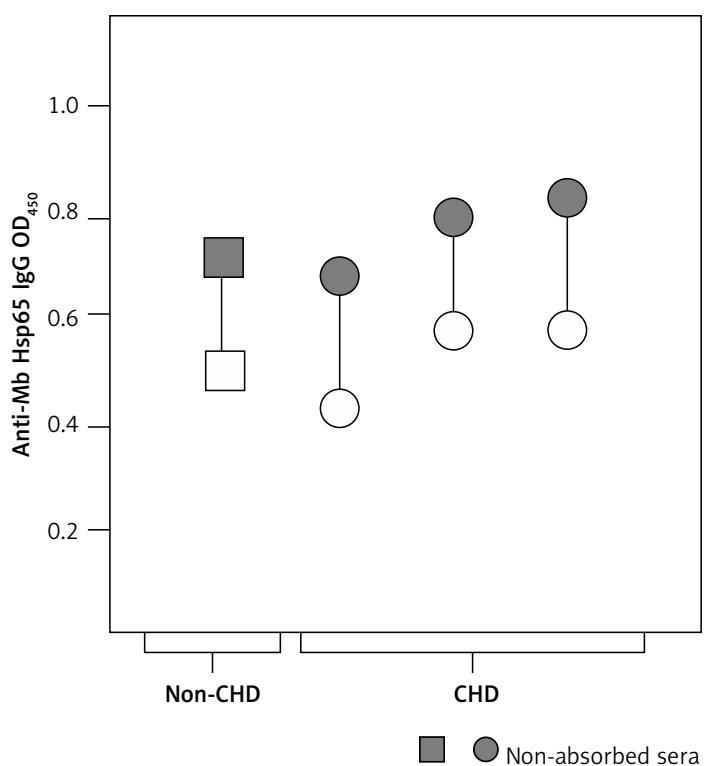

B

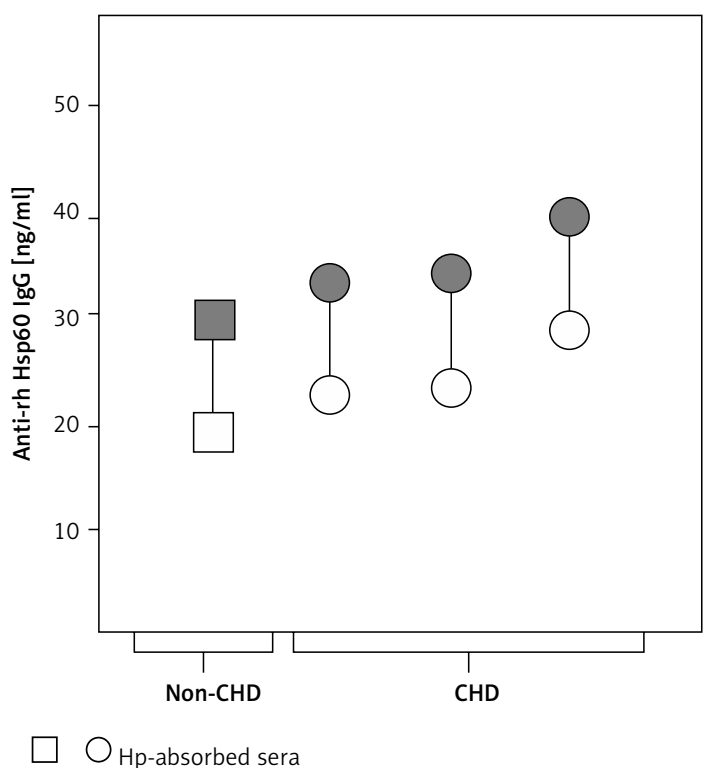

Figure 4. Reactivity of $H$. pylori (Hp)-positive sera from coronary heart disease (CHD) and non-CHD individuals, investigated in the ELISA assays with heat shock proteins (Hsp): M. bovis Hsp65 and human recombinant Hsp60 (rh Hsp60), expressed as optical density (OD) or ng/ml, respectively. Serum samples nonabsorbed (full figures) and absorbed (empty figures) with heat-inactivated $\mathrm{Hp}$ were used

\section{Discussion}

Since $\mathrm{Hp}$ induces a chronic inflammatory response, such infections could amplify the atherosclerosis-related pathologies. This indirect acceleration may involve inflammatory mediators induced by infection as well as specific antibodies with cross-reacting potency. The study supports the idea that chronic exposure to $\mathrm{Hp}$ in CHD patients may result in the increase of serum LBP and the production of antibodies against $\mathrm{Hp} \mathrm{HspB}$, cross-reacting with human Hsp60, both of which may facilitate the inflammation in the vascular endothelium. The pathological role of LBP may depend on the phenotype of vascular endothelium, which exhibits proinflammatory features such as increased PRR expression. The involvement of anti-Hsp60 lgs in CHD-related processes can be explained by the antigenic mimicry and complement dependent cell damage, possibly induced by such antibodies. The main limitation of most studies on the relationship of $\mathrm{Hp}$ infections and CHD is the lack of data on the duration of such infections. In this study the majority of CHD patients were chronically exposed to $\mathrm{Hp}$, since their serum samples contained both anti-Hp $\operatorname{lgG}_{2}$ and IgA occurring in chronic infections, as a result of immunoglobulin class switching. Previously, we reported the lack or very rare production of anti-Hp IgA in Hp infected children, and increasing occurrence of such antibodies in $\mathrm{Hp}$-infected adolescents or adults, suggesting that specific anti-Hp IgA appears later during infection [31]. In the present study we found that the CHD group was characterized by higher levels of both anti-Hp $\operatorname{lgG}_{2}$ and IgA. In research of others, $\operatorname{lgG}_{2}$ against $\mathrm{Hp}$ antigens was found to be dominating during chronic $\mathrm{Hp}$ infections, whereas the $\operatorname{lgG}_{3}$ subclass was typical for the acute stage [30]. The development of a humoral response in both classes of immunoglobulins may reflect the nature of antigens. Domination of $\operatorname{lgG}_{2}$ could be a consequence of the immune response to polysaccharide antigens, including lipopolysaccharide (LPS). The binding of LPS to toll-like receptors (TLR) on phagocytes and $B$ lymphocytes results in the secretion of TNF- $\alpha$ which activates dendritic cells and thereby enhances the activation of $\mathrm{CD}^{+} \mathrm{T}$ cells, which promote the production of $\operatorname{IgG}_{2}$ [32]. The overproduction of TNF- $\alpha$ is a characteristic feature of various cardiovascular disorders including $\mathrm{CHD}[5,6]$. It was postulated that antibodies induced by $\mathrm{Hp}$ LPS may potentiate CHD-related pathologies due to the recognition of common bacterial and host Lewis $^{\mathrm{XY}}$ determinants [33]. Intense production of anti-Hp IgA in CHD patients might be a result of the prolonged exposure to Hp protein antigens, such as Hsp, which can be effectively presented to immunocompetent cells of the mucosal immune system [32].

In the CHD group, elevated levels of total IgA but not IgG were detected more frequently than in the non-CHD donors. IgG levels can be affected by protein loss, infections and the use of drugs. In CHD individuals, enhanced diffusion and accumulation of IgG immune complexes (ICS) into the 
arterial walls was previously observed [34]. The negative modulation of the IgG humoral response by periodontitis-inducing microbes such as Actinomyces actinomycetemcomitans in CHD patients cannot be excluded [35]. An increased concentration of IgA in CHD patients could have also been a result of chronic exposure of the host immune cells to various antigens of Moraxella, Bordetella, Propionibacterium, Campylobacter, Chlamydia, Salmonella, Borrelia, Legionella, Haemophilus and Pseudomonas species [36]. Another reason for the elevated levels of serum IgA in Hp-positive CHD patients could be the domination of IgA monomers due to the down-regulation of the $\mathrm{J}$ chain synthesis induced by $\mathrm{Hp}$ during infection [37]. IgA could be involved in the development of post-infection autoimmune processes, which are supposed to be involved in the development of atherosclerosis [38].

Vascular endothelium may be dysregulated due to the overexpression of inflammatory markers induced by infection [39] or endogenous compounds [2-6]. The list of inflammatory markers which correlate with atherosclerosis includes various cytokines and chemokines, for instance TNF- $\alpha$, IL-6 [8], monocyte chemoattractant protein (MCP-1), fibrinogen, CRP, adhesion molecules such as selectins and vascular cell adhesion molecule-1 (VCAM-1), as well as myeloperoxidase and metalloproteinase involved in lipid peroxidation and accelerated consumption of nitric oxide (NO) [4042]. Attention was also paid to the role of the cellular signaling pathways involving CD14, TLR and $\operatorname{LBP}[43,44]$, with the latter being considered as a protein triggering pathological symptoms during CHD [45].

In this study the levels of LBP were found to be significantly higher in the CHD than in the nonCHD group. Type I Hp strains, inducing a strong inflammatory response [45], were able to trigger LBP overproduction. This was visualized by higher levels of LBP in the non-CHD donors exposed to type I Hp strains. The effectiveness of type I Hp strains to stimulate LBP production in the CHD patients was probably masked due to the overproduction of this acute phase protein in response to atherosclerosis-caused pathology. In the previous study [33] it was shown that in CHD Hp negative individuals the level of LBP was significantly higher than in $\mathrm{Hp}$ negative healthy controls, which suggests that the atherogenic processes influence the level of LBP.

Similarly, CRP concentrations in plasma of CHD patients increase in response to infections or tissue damage, which may be a consequence of cardiovascular disorders [42]. In CHD patients high levels of LBP may be involved in the binding and transportation of oxLDL and/or bacterial LPS, which may lead to the deposition of these compounds on endothelial cells, thus accelerating inflammatory processes that promote CHD-related pathologies [37, 46]. It was shown that TLR4 may function intracellularly in human coronary artery endothelial cells and via LBP and SCD14 proteins mediates LPS responses [47]. A limitation of these studies is that they do not allow combining the results of routine CRP and experimental LBP measurements with in flammatory markers in gastric epithelium, which may induce systemic effects [42]. However, experimental works on mice models showed that chronic Hp infection induces the upregulation of VCAM-1 expression and thrombosis parameters and downregulation of NO synthesis, which supports a possible role of these microorganisms in atherogenesis [48, 49].

Immunological cross-reactivity was considered as a possible mechanism of CHD-related pathologies [50]. In this study the increased prevalence of anti-Hp HspB Ig was related to the high frequency of $\mathrm{Hp}$ exposure in CHD patients. The concentration of anti-Hp HspB Ig in Hp-positive sera was reduced by its absorption, with inactivated $\mathrm{Hp}$ bacteria. The absorption assay showed the cross-reactive nature of $\mathrm{Hp}$-induced anti-Hp HspB antibodies. In vivo anti-HspB IgG may interact with human Hsp60, overexpressed in the vascular endothelium of CHD individuals, and trigger complement-dependent disorders. Some pathological effects could be induced in CHD patients by ICS containing Hp LPS and anti-Hp LPS IgG $[25,33]$ or by anti-CagA antibodies reacting with the host antigens on endothelial cells, uncovered during the inflammatory process [40, 51].

In conclusion, the present study supports the hypothesis of a relationship between $\mathrm{Hp}$ infections and CHD, which may result from the elevated levels of LBP and cross-reacting anti-Hsp60 IgG.

\section{Acknowledgments}

The study was supported by grants from the University of Lodz.

\section{Conflict of interest}

The authors declare no conflict of interest.

\section{References}

1. Chmiela M, Michetti P. Inflammation, immunity, vaccines for Helicobacter infection. Helicobacter 2006; 11 (Suppl. 1): 21-6.

2. Libby P, Theroux P. Pathophysiology of coronary artery disease. Circulation 2005; 111: 3481-8.

3. Chałubiński M, Wojdan K, Dorantowicz R, Jackowska P, Grzelak P, Broncel M. Comprehensive insight into im- 
mune regulatory mechanisms and vascular wall determinants of atherogenesis-emerging perspectives of immunomodulation. Arch Med Sci 2013; 9: 159-65.

4. Ertek S, Cicero A. Impact of physical activity on inflammation: effects on cardiovascular disease risk and other inflammatory conditions. Arch Med Sci 2012; 8: 794-804

5. Kleinbongard P, Schultz R, Heusch G. TNF-alpha in atherosclerosis, myocardial ischemia/reperfusion, remodelling and heart failure. Heart Fail Rev 2011; 16: 49-69.

6. Baars T, Konorza T, Kahlert P, et al. Coronary aspirate TNF-alpha reflects saphenous vein bypass graft restenosis risk in diabetic patients. Cardiovasc Diabetol 2013; 12: 12 .

7. Espinola-Klein C, Rupprecht HJ, Blankenberg S, et al. Impact of infectious burden on progression of carotid atherosclerosis. Stroke 2013; 33: 2581-6.

8. Matsuura E, Kobayashi K, Matsunami Y, et al. Autoimmunity, infectious immunity and atherosclerosis. J Clin Immunol 2009; 29: 714-21.

9. Mendall MA, Goggin PM, Molineux N, et al. Relation of Helicobacter pylori infection and coronary heart disease. Br Heart J 1994; 71: 437-9.

10. Longo-Mbenza B, Nsenga JN, Mokondjimobe E, et al. Helicobacter pylori infection is identified as a cardiovascular risk factor in Central Africans. Vasc Health Risk Management 2012; 8: 455-61.

11. Jefferson SS, Gillespie BW, Aiello AE, Haan MN, Morgenstern LB, Lisabeth LD. Antibody levels to persistent pathogens and incident stroke in Mexican Americans. PLoS One 2013; 8: e65959.

12. Khodaii Z, Hosain VH, Ghaderian SM, Najar RA, Panah AS Association of Helicobacter pylori infection with acute myocardial infarction. Coron Artery Dis 2011; 22: 6-11.

13. Kowalski M, Rees W, Konturek PC, et al. Detection of $\mathrm{H}$. pylori specific DNA in human atheromatous coronary arteries and its association to prior myocardial infarction and unstable angina. Dig Liver Dis 2002; 34: 398-402.

14. Akbas HS, Basyigit S, Suleymanlar I, et al. The assessment of carotid intima media thickness and serum paraoxonase-1 activity in Helicobacter pylori positive subjects. Lipids Health Dis 2010; 9: 92.

15. Satoh H, Saijo Y, Yoshioka E, Tsutsui H. Helicobacter pylori infection is a significant risk for modified lipid profile in Japanese male subjects. J Atheroscler Thromb 2010; 17: 1041-8.

16. Wierzbicki AS. Homocysteine and cardiovascular disease: a review of the evidence. Diabetes Vasc Dis Res 2007; 4: 143-9.

17. Smiley ST, King JA, Hancock WW. Fibrinogen stimulates macrophage chemokine secretion through Toll-like re ceptor 4. J Immunol 2001; 167: 2887-94.

18. Polyzos SA, Kountouras J, Zavos C, Deretzi G. The association between Helicobacter pylori infection and insulin resistance: a systemic review. Helicobacter 2011; 16 79-88.

19. Schottker BEN, Adamu MA, Weck MN, Muller H, Brenner $\mathrm{H}$. Helicobacter pylori infection, chronic atrophic gastritis and major cardiovascular events: a population based cohort study. Atherosclerosis 2012; 220: 569-74.

20. Tsai CJ, Huang TY. Relation of Helicobacter pylori infection and angiographically demonstrated coronary artery disease. Dig Dis Sci 2000; 45: 1227-32.

21. Christodoulou DK, Milionis HJ, Pappa P, et al. Association of Helicobacter pylori infection with cardiovascular disease - is it just a myth? Eur J Intern Med 2011; 22: $191-4$
22. Tan HJ, Goh KL. Extragastrointestinal manifestations of Helicobacter pylori infection: facts or myth? A critical review. J Dig Dis 2012; 13: 342-9.

23. Kaulgud RS, Kamath RL. Early prognosis of unstable angina patients with positive $\mathrm{H}$. pylori IgG values. Int J Biom Res 2013; 4: 145-52.

24. Schöttker B, Adamu MA, Weck MN, Müller H, Brenner H. Helicobacter pylori infection, chronic atrophic gastritis and major cardiovascular events: a population-based cohort study. Atherosclerosis 2012; 220: 569-74.

25. Labarrere CA, Zaloga GP. C-reactive protein: from innocent bystander to pivotal mediator of atherosclerosis. Circulation 2004; 109: 27-33.

26. Gensini GG. A more meaningful scoring system for determining the severity of coronary heart disease. Am J Cardiol 1983; 51: 606.

27. Neeland IJ, Patel RS, Eshtehardi P, et al. Coronary angiographic scoring systems. An evaluation of their equivalence and validity. Am Heart J 2012; 164: 547-52.

28. Bielański W, Konturek SJ. New approach to $13 \mathrm{C}$ urea breath test capsule-based modification with low dose of $13 \mathrm{C}$ urea in the diagnosis of Helicobacter pylori infection. J Physiol Pharmacol 1996; 47: 545-53.

29. Rechciński T, Chmiela M, Małecka-Panas E, PłanetaMałecka I, Rudnicka W. Serological indicators of Helicobacter pylori infection in adult dyspeptic patients and healthy blood donors. Microbiol Immunol 1997; 41: 387-93.

30. Vorobjova T, Ren Z, Dunkley M, et al. Response of IgG1 and IgG2 subclasses to Helicobacter pylori in subjects with chronic inflammation of the gastric mucosa, atrophy and gastric cancer in a country with high Helicobacter pylori infection prevalence. APMIS 2006; 114: 372-80.

31. Chmiela M, Ławnik M, Czkwianianc E, Rechciński T, Płaneta-Małecka I, Rudnicka W. Systemic humoral response to Helicobacter pylori in children and adults. Arch Immunol Ther Exp 1998; 46: 161-7.

32. Weintraub A. Immunology of bacterial polysaccharide antigens. Carbohydr Res 2003; 338: 2539-47.

33. Grebowska A, Rechcinski T, Moran A, et al. Increased levels of immunoglobulin and non-immunoglobulin markers of host response to Hp LPS in the patients with coronary artery disease (CAD). Curr Trends Immunol 2006; 7: 85-96.

34. Sims FH, Gavin JB, Edgar S, Toelmeyer T. Diffusion of gammaglobulin into the arterial wall identifies localized entry of lipid and cells in atherosclerosis. Coron Artery Dis 2000; 12: 21-30.

35. Haynes WG, Stanford C. Periodontal disease and atherosclerosis: from dental to arterial plaque. Arterioscler Thromb Vasc Biol 2003; 23: 1309-11.

36. Muscari A, Bazzoli C, Puddu GM, et al. Increased serum IgA levels in subjects with previous myocardial infarction or other major ischaemic events. Cardiology 1993; 83: 383-9.

37. Berstad A, Kilian M, Valnes KN, Brandtzaeg P. Increased mucosal production of monomeric IgA1 but no IgA1 protease activity in Helicobacter pylori gastritis. Am J Pathol 1999; 155: 1097-104.

38. Virella G, Atchley D, Koskinen S, Zheng D, Lopes-Virella MF; the DCCTI/EDIC Research Group. Proatherogenic and proinflammatory properties if immune complexes prepared with purified human oxLDL antibodies and human oxLDL. Clin Immunol 2002; 105: 81-2.

39. Oshima T, Ozono R, Yano Y, et al. Association of Helicobacter pylori infection with systemic inflammation and 
endothelial dysfunction in healthy male subjects. J Am Coll Cardiol 2005; 45: 1219-22.

40. Davington J, Granz P. Role of endothelial dysfunction in atherosclerosis. Circulation 2004; 109 (Suppl. 1): 1127-32.

41. Sheikine Y, Hansson GK. Chemokines and atherosclerosis. Ann Med 2004; 36: 98-118.

42. Hirsch AT, Folsom AR. The continuum risk. Vascular pathophysiology, function and structure. Circulation 2004; 110: 2774-77.

43. Edfeldt $\mathrm{K}$, Bennet AM, Eriksson P, et al. Association of hypo-responsive Toll-like receptor 4 variants with risk of myocardial infarction. Eur Heart J 2004; 25: 1447-53.

44. Ferencik M, Stvrtinova V, Hulin I. Defects in regulation of local immune responses resulting in atherosclerosis. Clin Dev Immunol 2005; 12: 225-34.

45. Rozankovic PB, Huzjan AL, Cupic H, Bencic IJ, Basic S, Demarin V. Influence of CagA-positive Helicobacter pylori strains on atherosclerotic carotid disease. J Neurol 2011; 258: 753-61.

46. Lepper PM, Schumann C, Triantafilou K, et al. Association of lipopolysaccharide-binding protein and coronary artery disease in men. J Am Coll Cardiol 2007; 50: 25-31.

47. Dunzendorfer S, Lee MK, Soldau K, Tobias PS. Toll-like receptor 4 functions intracellularly in human coronary artery endothelial cells: roles of LBP and SCD14 in mediating LPS-responses. FASEB J 2004; 18: 1117-9.

48. Liuba P, Pesonen E, Paakkari I, et al. Co infection with Chlamydia pneumonia and $\mathrm{H}$. pylori results in vascular endothelial dysfunction and enhanced VCAM-1 expression in apoE-kockout mice. J Vasc Res 2003; 40: 115-22.

49. Agucjouf O, Mayo K, Montciro L, Doutrcmcpuich F, Doutremepuich C, Megraud F. Increase of arterial thrombosis parameters in chronic Helicobacter pylori infection in mice. Tromb Res 2003; 108: 245-8.

50. Erkkilä L, Laitinen K, Haasio K, et al. Heat shock protein 60 autoimmunity and early lipid lesions in choresterol-fed C57BL/6JBom mice during Chlamydia pneumoniae infections. Atherosclerosis 2004; 177: 321-8.

51. Franceschi F, Sepulveda AR, Gasbarrini A, et al. Cross-reactivity of anti-CagA antibodies with vascular wall antigens: possible pathogenic link between Helicobacter pylori infection and atherosclerosis. Circulation 2002; 106: 430-4. 